\title{
Learning Effects of the Lower Extremity Motor Coordination Test in Individuals with Stroke
}

\author{
Menezes KKP, Avelino PR, Scianni AA, Faria- \\ Fortini I, Faria CDCM, Nascimento LR and \\ Teixeira-Salmela LF* \\ Department of Physical Therapy, Universidade Federal de \\ Minas Gerais, Belo Horizonte, MG, Brazil \\ *Correspondling author: Luci Fuscaldi Teixeira- \\ Salmela, Department of Physical Therapy, Universidade \\ Federal de Minas Gerais. Avenida Antônio Carlos, 6627, \\ Campus Pampulha, 31270-901 Belo Horizonte, Minas \\ Gerais, Brazil
}

Received: March 02, 2017; Accepted: March 29, 2017; Published: April 04, 2017

\begin{abstract}
Background: The Lower Extremity Motor Coordination Test (LEMOCOT) is a simple test that requires the ability to execute movements with maximal capacity. Thus, it is possible that people would improve performance, due to the task learning. If the effects of learning during the repetition of tests are not considered, the results may lead to wrong conclusions regarding the benefits of interventions.
\end{abstract} stroke.

Objective: To evaluate the learning effects of the LEMOCOT in people with

Materials and Methods: The participants performed the LEMOCOT three times, first with their non-paretic, followed by their paretic lower limbs. The learning effects on the consecutive three trials of both lower limbs were assessed by investigating the differences in the LEMOCOT scores across the trials, using repeated measure ANOVAs with a significance level of $5 \%$.

Results: Forty-one individuals with stroke, 23 men, who had a mean age of 62 years (SD 12) and a mean time since the onset of the stroke of 56 months (SD 65), were evaluated. For both limbs, the LEMOCOT scores gradually increased, from the first to the third trial. Statistically significant differences in the LEMOCOT scores were found across the trials, for both the paretic and nonparetic lower limbs $(5.34<\mathrm{F}<24.31, \mathrm{p}<0.05)$. However, the maximal differences found between the three trials for both limbs were lower than the smallest real difference values reported for the LEMOCOT.

Conclusions: Although the LEMOCOT showed statistically significant learning effects, the differences due to learning appeared to be small and not clinically relevant.

Keywords: Learning Effect; Motor Skills; Lower Extremity; Stroke

\section{Abbreviations}

LEMOCOT: Lower Extremity Motor Coordination Test

\section{Introduction}

Adequate coordination of the lower limbs is important for the performance of daily living activities and for an independent life [1]. Loss of coordination is one of the main impairments, that contributes to disability after a stroke $[1,2]$. Usually, motor coordination is tested under conditions, in which some temporal and spatial accuracies are required [3]. In this line, the Lower Extremity Motor Coordination Test (LEMOCOT) was developed to quantitatively measure motor coordination of the lower extremity. It is simple, has good clinical utility, and showed to be the most suitable test to measure motor coordination of the lower limbs [3,4]. Recently, its psychometric properties were investigated and the results indicated that the LEMOCOT showed to be a valid and reliable measure of motor coordination for individuals with stroke [5].

The LEMOCOT consists of moving the lower extremity, as fast as possible, from one target to another for 20 seconds and the number of on-touched targets constitutes the final score [3]. During the test, the individuals are instructed not to sacrifice the accuracy of the touches, nor the quality of the movement to increase speed [3]. Thus, besides understanding the task, the subjects need the ability to execute the movements with their maximal capacity. Although a familiarization trial is allowed, it is possible that learning effects would occur, if the subjects increase their practice [6-8].

The effect of learning or practice is defined as an improvement in performance on the test by the subject, without having been offered any intervention or condition that could justify it [9]. Various reasons have been discussed to explain improvements induced by practice, such as reduced anxiety or increased familiarity with the testing environment and procedures [9]. Studies which do not consider the possibility of learning effects on the repetition of the tests, may lead to wrong conclusions regarding the benefits of interventions and even mask the presence of cognitive decline, primarily with the elderly population [10].

Therefore, to provide effective interventions to reduce lower limb motor coordination impairments after stroke, it is necessary to use valid and reliable measures. Considering that the LEMOCOT was considered the most suitable test for this purpose, the aim of the present study was to evaluate the learning effects of the LEMOCOT in people with stroke.
Phys Med Rehabil Int - Volume 4 Issue 1 - 2017 ISSN : 2471-0377 | www.austinpublishing group.com Teixeira-Salmela et al. (C) All rights are reserved
Citation: Menezes KKP, Avelino PR, Scianni AA, Faria-Fortini I, Faria CDCM, Nascimento LR, et al. Learning Effects of the Lower Extremity Motor Coordination Test in Individuals with Stroke. Phys Med Rehabil Int. 2017; 4(1): 1111. 


\section{Materials and Methods}

\section{Participants}

Community-dwelling people with stroke, who were living in a metropolitan city, were recruited from the general community, by screening out-patient clinics and University hospitals. The inclusion criteria were: $\geq 20$ years of age; at least three months since the onset of the stroke; weakness and/or increased tonus of the paretic lower limb muscles, as determined by $15 \%$ strength differences between the paretic and non-paretic limbs [11] and/or scores different from zero on the modified Ashworth Scale [12]; and absence of cognitive impairments, as determined by the education-adjusted cut-off scores on the Mini-mental state examination [13]

\section{Procedures}

Based upon previous approval from the University ethical review board, eligible participants were informed about the objectives of the study and provided written consent. The data were collected by welltrained physical therapists.

The participants performed the LEMOCOT three times, first with their non-paretic, followed by their paretic lower limb. They sat on an adjustable chair with their feet resting flat on thin rigid foam, heels on the proximal target, and with knees and hips at $90^{\circ}$ of flexion [3]. Then, after a familiarization trial, they were instructed to alternately touch the proximal and distal targets, placed $30 \mathrm{~cm}$ apart, with their big toe, for 20s, as fast as possible, without sacrificing the accuracy to increase speed [3]. The number of touched targets was counted and registered for analyses.

\section{Statistical analyses}

The analyses were carried-out with the SPSS software for Windows with a significance level of 5\%. Descriptive statistics and tests for normality and equality of variances were calculated for all outcomes. The learning effects were evaluated, using Repeatedmeasure ANOVA to investigate differences in the LEMOCOT scores between the three trials for both the paretic and non-paretic lower limbs.

\section{Results and Discussion}

Forty-one individuals with stroke, 23 men, who had a mean age of 62 years (SD 12) and a mean time since the onset of the stroke of 56 (65) months, were evaluated. Their descriptive data are summarized in Table 1. The LEMOCOT scores of both limbs gradually increased from the first to the third trial. ANOVA revealed significant differences regarding the LEMOCOT scores across the three trials, for both the paretic and non-paretic lower limbs, as shown in Table 2 $(5.34<F<24.31, p<0.05)$.

This study aimed at investigating the learning effects of the LEMOCOT, which is a simple and suitable test to evaluate lower limb motor coordination. The results showed significant differences in the mean scores across the three trials, for both the paretic and non-paretic lower limbs. The scores gradually increased from the first to the third trial, evidencing statistically significant learning effects.

However, although the statistical results revealed significant effects, the differences in scores across the trials should be evaluated with caution. To be able to detect real clinical changes, the differences

Table 1: Participants' characteristics.
\begin{tabular}{|c|c|}
\hline Variable & $n=41$ \\
\hline Sex, men, $\mathrm{n}(\%)$ & $23(56)$ \\
\hline Age (years), mean \pm SD (range) & $62 \pm 12(31-81)$ \\
\hline Time since stroke (months), mean \pm SD (range) & $56 \pm 65(3-196)$ \\
\hline Paretic side, right, $n(\%)$ & $18(44)$ \\
\hline
\end{tabular}

*SD= Standard deviation.

Table 2: LEMOCOT scores (means $\pm S D$ ) for both the paretic and non-paretic lower limbs and the differences between the trials for both the paretic and nonparetic lower limbs.

\begin{tabular}{|c|c|c|c|c|}
\hline \multirow{2}{*}{$\begin{array}{c}\text { Lower } \\
\text { limb }\end{array}$} & \multicolumn{3}{|c|}{ LEMOCOT SCORES } & \multirow{2}{*}{ F, p values } \\
\cline { 2 - 5 } & First trial & Second trial & Third trial & \\
\hline Paretic & $12.90(11.40)^{\mathrm{a}}$ & $13.54(11.63)^{\mathrm{b}}$ & $14.63(12.44)^{\mathrm{c}}$ & $\begin{array}{c}5.34<\mathrm{F}<24.32 \\
0.001<\mathrm{p}<0.05\end{array}$ \\
\hline $\begin{array}{c}\text { Non- } \\
\text { paretic }\end{array}$ & $27.68(8.76)^{\mathrm{a}}$ & $29.46(9.04)^{\mathrm{b}}$ & $31.00(9.72)^{\mathrm{c}}$ & $\begin{array}{c}19.92<\mathrm{F}<23.26 \\
\mathrm{p}<0.001\end{array}$ \\
\hline
\end{tabular}

LEMOCOT = Lower extremity motor coordination test.

In each column, different letters indicate statistical significant differences.

between the scores generated by two or more independent evaluations should be greater than the error values $[14,15]$. The magnitude of these errors is measured by the smallest real difference, which is estimated by the standard error of the measurement [16]. A recent study investigated the standard error of measurement of the LEMOCOT and found values of 1.23 and 1.56 for the paretic and non-paretic lower limbs, respectively [5]. Based on these data, the smallest real differences were also calculated and values of 3.41 and 4.32 were reported for the paretic and non-paretic lower limbs, respectively [5]. That is, for significant changes to be detectable, the changes in the scores should exceed these values. However, in the present study, the maximal difference values found across the three trials were 1.09 and 1.78 , for the paretic and non-paretic lower limbs, respectively. Thus, although the LEMOCOT showed statistically significant learning effects, the differences due to learning are quite small and do not have potential to clinically impact the measure.

The best scoring methods of the LEMOCOT were also previously investigated and the results corroborated the present findings [5]. The following scoring methods were evaluated: first trial, the mean of the first two trials, the mean of the last two trials, and the mean of the three trials. The results also revealed statistically significant differences regarding all scoring methods for both the non-paretic and paretic lower limbs. However, the values were lower than those of the standard error of the measurement and smallest real difference, suggesting that any of them could be used [5]. Although these results gave an indication regarding the learning effects of the LEMOCOT, these findings should be interpreted with caution. First, the authors did not report whether the mean scores gradually increased from the first to the third trial. Second, to analyze the best scoring method, they investigated the differences in the mean values across the trials. However, the mean tends to soften the differences between two values [14], which could have omitted the presence of a learning effect, which would only be evidenced by individual analysis of the trials, as was performed in the present study.

\section{Study Limitations}

Although a previous study raised the possibility of learning effects of the LEMOCOT, this is the first study to specifically investigate these 
effects. However, some limitations may be cited. First, the sample was drawn from various settings and was not randomly selected, and may not, therefore, be fully representative of the stroke population. Furthermore, the present study did not evaluate learning effects over time. However, adequate test-retest reliability between the scoring methods of the LEMOCOT was reported [5].

\section{Conclusion}

Statistically significant differences in the LEMOCOT scores across the three trials were found for both paretic and non-paretic lower limbs. However, these differences were not clinically significant. Therefore, although the LEMOCOT showed statistically significant learning effects, the differences due to learning appeared to be small and not clinically relevant.

\section{Funding}

This research was supported by the Brazilian Funding Agencies: CNPq [grant number 471324/2013-2]; and FAPEMIG [grant number 00006-14].

\section{References}

1. Carr JH, Shepherd RB. Neurological rehabilitation: optimizing motor performance. $2^{\text {nd }}$ ed. Oxford: Churchill Livingstone. 2010.

2. Ada L, Canning C. Changing the way we view the contribution of motor impairments to physical disability after stroke. Refshauge K, Ada L, Ellis E, editors. In: Science-based rehabilitation: theories into practice. Elsevier. 2005; 87-106.

3. Desrosiers J, Rochette A, Corriveau H. Validation of a new lower-extremity motor coordination test. Arch Phys Med Rehabil. 2005; 86: 993-998.

4. Pinheiro MB, MenezesKKP, Teixeira-Salmela LF. Review of the psychometric properties of lower limb motor coordination tests. Fisioter Mov. 2014; 27 : 541 553.

5. Meneezes KKP, Scianni AA, Faria-Fortini I, Avelino PR, Faria CDCM Teixeira-Salmela LF. Measurement properties of the Lower Extremity Motor
Coordination Test in individuals with stroke. J Rehabil Med. 2015; 47: 502 507.

6. Wu G, Sanderson B, Bittner V. The 6-minute walk test: How important is the learning effect? Am Heart J. 2003; 146: 129-133.

7. Larson JL, Covey MK, Vitalo CA, Alex CG, Patel M, Kim MJ. Maximal inspiratory pressure. Learning effect and test-retest reliability in patients with chronic obstructive pulmonary disease. Chest. 1993; 104: 448-453.

8. Awad LN, Kesar TM, Reisman D, Binder-Macleod AS. Effects of repeated treadmill testing and electrical stimulation on post-stroke gait kinematics. Gait Posture. 2013; 37: 67-71.

9. Salthouse TA, Toth J, Daniels K, Parks C, Pak R, Wolbrette M, et al. Effects of aging on efficiency of task switching in a variant of the trail making test. Neuropsychology. 2000; 14: 102-111.

10. Calamia M, Markon K, Tranel D. Scoring higher the second time around: meta-analyses of practice effects in neuropsychological assessment. Clin Neuropsychol. 2012; 26: 543-570.

11. Faria CDCM, Teixeira-Salmela LF, Nadeau S. Predicting levels of basic functional mobility, as assessed by the Timed "Up and Go" test, for individuals with stroke: discriminant analyses. Disabil Rehabil. 2013; 35: 146-152.

12. Gregson JM, Leathley M, Moore AP, Sharma AK, Smith TL, Watkins CL. Reliability of the tone assessment scale and the modified Ashworth scale as clinical tools for assessing post stroke spasticity. Arch Phys Med Rehabil. 1999; 80: 1013-1016.

13. Bertolucci P, Brucki S, Campacci S, Juliano Y. The Mini-Mental state examination in an outpatient population: influence of literacy. Arq Neuropsiquiatr. 1994; 52: 1-7.

14. Portney LG, Watkins MP. Foundations of clinical research: applications to practice. $3^{\text {rd }}$ ed. Upper Saddle River: Prentice-Hall. 2009.

15. Tyson SF. Measurement error in functional balance and mobility tests for people with stroke: what are the sources of error and what is the best way to minimize error? Neurorehabil Neural Repair. 2007; 21: 46-50.

16. Beckerman H, Roebroeck ME, Lankhorst GJ, Becher JG, Bezemer PD, Verbeek AL. Smallest real difference, a link between reproducibility and responsiveness. Qual Life Res. 2001; 10: 571-578.
Phys Med Rehabil Int - Volume 4 Issue 1 - 2017

ISSN : 2471-0377 | www.austinpublishinggroup.com

Teixeira-Salmela et al. (C) All rights are reserved
Citation: Menezes KKP, Avelino PR, Scianni AA, Faria-Fortini I, Faria CDCM, Nascimento LR, et al. Learning Effects of the Lower Extremity Motor Coordination Test in Individuals with Stroke. Phys Med Rehabil Int. 2017; 4(1): 1111. 